\title{
Research on Enterprise Marketing Strategy Based on Product Life Cycle Theory \\ Jian $\mathrm{Xu}^{1}$
}

${ }^{1}$ Qujing normal college, yunnan qujing city kirin sanjiang avenue, 655011

14027400@qq.com

Keywords: Product; Product life cycle; Marketing; Marketing strategy

\begin{abstract}
Nowadays, with the improvement of consumer's consumption level, the consumption demand and level are also improving. Satisfying the market consumption demand, attracting the target consumers, grabbing the market share and winning the biggest profit are the focus of business management. The application of product life cycle theory is of great significance for the enterprise to carry out marketing activities. On the basis of the analysis of the theory of product life cycle and the positive significance, this paper puts forward the corresponding marketing strategy.
\end{abstract}

With the intensification of market competition, marketing plays an increasingly important role in the management of enterprises, and the formulation of marketing strategy has great significance for enterprises. There are many factors to consider in the formulation of marketing strategy, and the product life cycle is an important factor. It has a direct impact on the formulation of product marketing strategy. The product life cycle refers to the whole process from product entry to market withdrawal, which is divided into four stages: introduction, growth, maturity and recession. Each period reflects the different characteristics of customers, competitors, dealers and profit status. " [1] marketing activities should take market demand as the starting point and provide products to meet the specific needs of consumers, so the product life cycle is affected by the life cycle of demand and technology. The life of the product is limited. It is different from the life of the product. It is relative to the life and life of the product. When the product is in different stages of the life cycle, the market characteristics are different. Every stage will bring different requirements and challenges to the enterprise and marketer, and the marketing strategy of the product will also change.

The product life cycle is just the introduction of products put into the market, consumers do not understand the basic products, sales slow growth stage; growth stage is introduced after the adaptation period, has been the target consumer acceptance of products, sales of fast rising phase; mature period is the product sales rose limited space, product sales and profit slow rising or falling stage; the recession is the product profit in the market decreases rapidly and tends to zero gradually, until the product out of the market stage. Products are in different stages of life cycle, and their marketing goals, competitive environment and advertising strategies are different. "One of the most important prerequisite for corporate decision-making is the judgment and a good grasp of the product life cycle, this requires us to analyze specific issues, according to the actual situation of the enterprises themselves to judge the product at any stage of the product life cycle, thus to predict the future and its development trend." [2]

\section{The Positive Significance of the Life Cycle of the Product}

Enhance the Consciousness of the Enterprise. The product life cycle theory reveals the state and characteristics of products in different periods of the market, and at the same time, it reflects the whole life movement process and the development rule of products in the market. Due to the change of market environment, the transfer of consumption demand, the fierce competition environment, the emergence of alternative products, the level of marketing management and so on, the limited life of products in the market and so on. The enterprise should strengthen the theory of product life cycle management, strengthen the enterprise management of the entire process of marketing, enhance their sense of urgency, so be prepared to grasp the changes in products at 
various stages in the market, to better meet the market demand and changes.

Guide Enterprises to Improve their Innovation Ability. The demand of consumers will change with the change of time, environment and so on. In order to realize the development, the enterprise must meet the market consumption demand to the greatest extent. Innovation is the function of the modern enterprise. The management of the product life cycle theory can actively guide the enterprise to improve the innovation ability. First, managers and marketers should have the spirit of innovation; secondly in order to better meet the needs of enterprises in various stages of product life cycle, continuous improvement of existing products and development of new products, the products from the design, performance, quality, packaging and other aspects of innovation, prolong the life cycle of products.

Be Good at Discovering Market Opportunities. As the product is different in the life cycle of the product, its market characteristics are also different. The enterprise marketing managers analyze each stage of the life cycle of the product, which is helpful to discover more market opportunities hidden in each stage. If marketing managers seize these market opportunities and formulate targeted marketing strategies according to the market characteristics of different stages, they will enhance their competitive advantage and stabilize their market position, so that they can survive and develop.

Dare to Deal with the Challenge. In the modern market, enterprises are always in the competitive environment. They will face challenges from competitors all the time, and healthy competition among enterprises can drive the development of the market. Due to fierce market competition forced the enterprises to study the product, the stage of the product life cycle, clear characteristics of products, improve product technology, to ensure product quality, improve marketing management level, enhance the core competitiveness of enterprises to take time for market challenges.

\section{Enterprise Marketing Strategy at Various Stages of Product Life Cycle}

Penetration and Plunder Strategy. According to the introduction of products, enterprises should first solve is how to quickly enter the market, so that consumers understand and familiar with the products, timely collect the views of consumers, the formation of feedback, in order to promote the quality of products and technology continue to improve, to lay a solid foundation for entering a period of growth. The stage of enterprise's marketing strategy has four main strategies: one is when the product market demand, the consumer desires to get products, enterprises in order to enter the market as soon as possible, to meet consumer demand, profit, and as soon as possible to recover the cost of investment and take the high price and high promotion combination skimming strategy. Two is the new product features or to fill the blank of the corresponding effective market situation, consumers need products for higher degree, high prices can also be accepted by consumers, the market competition environment, enterprises adopt high price and low promotion combination of skimming strategy in order to maximize profits and rapid realization of product. Three, when consumers are not aware of new products, they are more sensitive to product prices, large market demand and fierce competition environment. In order to get consumers' recognition and get a certain market share as soon as possible, enterprises adopt a fast penetration strategy combining high promotion and low price. The four is when the consumer products have been gradually understand, the size of the market is relatively large, more interested in product prices, new competitors continue to join the competition, expanding the ranks of enterprises, in order to make more consumers accept the products and get more net profit by low price and low promotion combination of slow penetration strategy. When introducing products, enterprises should emphasize the characteristics of "fast", no matter which strategy should be taken, enter the market quickly, increase popularity, quickly get the recognition of consumers and seize the market.

Expansion Strategy. The product has been approved by the market, and has a certain number of consumer groups. The product has entered the growth period, and the sales volume and profit are increasing. For the growth of products, the core of business marketing is how to extend the growth period of products, achieve the maximum profit time, and increase the market growth rate and 
market share. The main marketing strategies in this stage are as follows: one is to improve the quality of the products. With the improvement of product technology, in order to ensure product quality and to better meet consumer demand, enterprises should constantly improve product quality and provide better after-sales service. The two is to strengthen the promotion. Through vigorous promotion and advertising, to improve the reputation and reputation of the product, to establish a good product image. The three is to develop and expand the new market. According to product characteristics and market demand, we should carry out reasonable market segmentation, develop new market actively, expand target market range, and develop targeted marketing mix strategy based on original market share. The four is to consolidate and expand marketing channels. "Channel resources are a scarce strategic resource. It is not only an important source of enterprise market information, but also a weapon to establish competitive advantage. [3] consolidates the established marketing channel, and makes it more perfect and ideal. At the same time, we should increase and expand new marketing channels according to the market demand and the way of consumers' purchase, so as to meet the change of demand. The five is to adjust the price. In order to fully attract consumers, stimulate their buying behavior and show their competitive advantages, enterprises should adjust product prices or promotions according to the right time and time. In the growth period, enterprises should highlight the characteristics of "good", take the expansion strategy, extend the life cycle of products, enhance the competitiveness of enterprises, and gain greater profit margins.

Improvement Strategy. When the product comes into maturity, sales and profits have slowed down. Due to the increase of sales volume and profit, the maturity of the product has decreased, and it even has a declining trend after reaching saturation state. The focus of enterprise marketing is how to consolidate its target market, maintain the existing consumer groups, extend the maturity of the product and maximize the profit. In view of the mature product, the enterprise should strengthen the improvement from the market, the product and the marketing mix. Such as market improvement: by improving the frequency of consumers' use of products, increasing the use of products, perfecting, developing and extending new uses and functions of new products, developing new markets, striving for potential customers and other measures to improve the market. For example, product improvement: in order to better meet the market demand changes, we can improve product performance and use methods, further improve product quality, highlight product characteristics and personalities, develop new features of products, and attract consumers. For example, marketing mix improvement: the product marketing mix is improved by adjusting the price, establishing new sales channels and changing the promotion strategy. In the mature products, enterprises emphasize the product's "excellent" through a series of improvement measures, so as to consolidate the market and avoid the loss of the inherent consumption groups and market segments, so as to extend the life cycle of the products.

Maintenance, Contraction, and Abandonment Strategies. As a result of the decline in the product, sales and profits are rapidly declining, and even a unprofitable situation. Therefore, at this stage, enterprises should delay sales and profits decline, gain profits or try to recover costs, and adopt strategies of maintaining, shrinking or abandoning. For example, maintenance strategy: there is still a certain market demand and profit space. Enterprises can keep the original market segments, adjust marketing strategies, keep sales volume at a certain level until they withdraw from the market Such as contraction strategy: enterprises can not maintain the original market segments, they can concentrate their resources on competitive market segments, reduce the profit less market and shrink the market share to make profits. Such as giving up strategy: when the market prospect is not optimistic, consumers are transferred a lot, and there is little profit or even no profit, enterprises should try to recover their cost and give up products and quit the market.

\section{Conclusion}

Under the guidance of the marketing concept of consumer and society, enterprises must have broader development space and win the market. We must enhance their competitive advantages and consolidate their strong market position. Enterprises and marketers should attach importance to 
product lifecycle theory management. Products are at different stages of life cycle, and their market characteristics are different, which will directly affect the choice of marketing strategies. The in-depth analysis and research of product life cycle theory can provide a scientific basis for enterprises to choose the right marketing strategy, and also can win more market opportunities for enterprises, and is conducive to the development of enterprises.

\section{Reference}

[1] L.L. Zhao: A Brief Description of the Life Cycle of the Product and the Corresponding Marketing Strategy,(2011) No.6, p.64-65. (In Chinese)

[2] L. Zhao: A Brief Discussion on the Relationship Between Product Life Cycle and Marketing Strategy,(2015) No.17, p.76-77. (In Chinese)

[3] Z.Y. Lin: Selection of New Product Channel Strategy Based on Product Life Cycle Theory, (2006) No.1, p.120-121. (In Chinese) 